\title{
Artificial Intelligence in Enforcement: Epistemological Analysis
}

\author{
Alexey I. Ovchinnikov ${ }^{1,2}$, Alexey Yu. Mamychev ${ }^{3}$, Tatiana S. Yatsenko ${ }^{4}$, Artur Kravchenko ${ }^{5} \&$ Yuri A. \\ Kolesnikov $^{6}$ \\ ${ }^{1}$ Department of Theory and History of State and Law, South Federal University, Russia \\ ${ }^{2}$ Department of Constitutional and Municipal Law, Russian Presidential Academy of National Economy and \\ Public Administration, Russia \\ ${ }^{3}$ Department of Theory and History of Russian and Foreign Law, Vladivostok State University of Economics \\ and Service, Vladivostok, Russia \\ ${ }^{4}$ Civil Law Department, Southern Federal University, Russia \\ ${ }^{5}$ Department of Civil Law Disciplines, Far Eastern Federal University, Russia \\ ${ }^{6}$ Financial Law Department, Southern Federal University, Rostov-on-Don, Russia \\ Correspondence: Alexey Yu. Mamychev, Department of Theory and History of Russian and Foreign Law, \\ Vladivostok State University of Economics and Service, Vladivostok, Russia. E-mail: mamychev@yandex.ru
}

Received: April 4, 2020

doi:10.5539/jpl.v13n2p75
Accepted: May 20, $2020 \quad$ Online Published: May 25, 2020

URL: https://doi.org/10.5539/jpl.v13n2p75

This article was prepared with the financial support of the RFBR grant No. 19-011-00820 (a) "The legal policy of the Russian state, its priorities and principles in the digital economy and digital technological order: conceptual, methodological, sectoral aspects of digitalization of law and legal regulation"

\begin{abstract}
The presented study examines the epistemological and philosophical and legal problems of the introduction of artificial intelligence systems in law enforcement. The article discusses the problematic implementation and use of artificial intelligence to automate the enforcement process, the judiciary and public administration. It is shown that the latter is considered without taking into account a key factor - the specifics of the intellectual process of bringing the general norm to a particular case. The authors show that for artificial intelligence systems, the contextuality of the principles of law is not achievable, while it is extremely necessary in law enforcement. In AI, contextual intellectual procedures cannot be programmed, since the ratio between the norm and the context of its interpretation involves a break through the hermeneutic circle in which the norm is a part and the context of the norm (industry principles) is a whole. The limited possibilities of using artificial intelligence systems in justice are also discussed, it is proved that digitalization in this area will be only instrumental in nature, and the administrative functions of robotic technologies are quite problematic and generally ineffective in the spiritual, moral and ethical dimension.
\end{abstract}

Keywords: artificial intelligence, law, law enforcement, justice, digitalization

\section{Introduction}

The key factor and the dominant trend in the development of various spheres of the life of modern society (economics, politics, law, culture, etc.) is the digitalization of social relations (The World in the Digital Age: Politics, Law, 2020). At the moment, there is no social interaction that does not feel the influence of digital technology. In private life, more and more of our interaction is already being realized through digital aggregators (intermediaries), in public relations the forms of digital communication and network technologies of public-power interaction are also very much developed (Robots claim their rights: doctrinal legal principles and moral and ethical standards for the use of autonomous robotic technologies and devices, 2020). The latter is also characteristic of the legal sphere. All modern political, legal and socio-economic development is directly linked to the digital transformation of society and all spheres of public life, as was already mentioned at the last legal forum in Moscow, St. Petersburg and other cities (Legal Understanding in the Digital Age: Artificial Intelligence in the Implementation of Law in Law Enforcement, 2019; Digital security of the individual, society and the state in the context of globalization: legal support mechanisms. Review of the session in the framework of SPBILF 
2019).

The most significant importance is currently attached to the system of public administration, justice, law enforcement. It is believed that with the introduction of digital forms and network technologies, these areas will significantly increase their effectiveness. More and more voices are heard in favor of the transfer of justice to some supposedly independent and objective robot judges who will be free from the dominant opinion of the leadership in the process of making decisions that are crucial for a person and selfish motivation. Their work is no longer science fiction: the European Union even adopted the "Ethical Charter of Artificial Intelligence in the Judiciary" (Beketov' ${ }^{2019)}$.

The problem is that artificial judges, even more than people, can depend on various preferences, for example, racial, socio-economic, religious and other prejudices, as they predict human behavior based on such facts as personal status, level of education, employment, etc., as well as the fact that human thinking is much more flexible, more accurate and more deeply implements legal conclusions: the danger lies in even greater algorithmization of justice than now, in its mechanization and routinization. We believe that automation of justice is possible, but only within the framework of banal, routine procedures for processing standard documents, nothing more.

One of the most pressing problems of our time - the use of artificial intelligence (hereinafter AI) to automate the law enforcement process is often considered beyond the main question - the specifics of the intellectual process of bringing the general norm to a particular case. In the field of law, this issue is central and most important for legal epistemology. Juristic or legal epistemology is a section of the philosophy of law dedicated to the analysis of the process of legal knowledge, legal thinking and legal understanding from epistemological, methodological, cognitive and other positions. Its tasks include the study of structure, methodology, semantic and contextual organization of both scientific and professional knowledge of law, legal reality, legal values.

Within its framework, the problem and specifics of legal knowledge and cognition, the cognizability of the essence of law, the concept of legal truth, structure, structure, dynamics, evolution of legal thinking are considered. Legal epistemology includes the epistemology of law as one of its paradigms, since the latter is based on one of the possible versions of legal thinking, understood as cognition, a reflection of law that arose in modern times in connection with the Cartesian distinction between the subject and the object of cognition. Epistemology of law or legal epistemology includes various paradigms of legal thinking, studies legal thinking itself, based on the structure of legal knowledge. After all, the latter exists not only as a result of knowledge of law, but also as an element of the human inner world, as a legal consciousness, legal archetype, legal intuition, etc. Legal epistemology includes problems: How is knowledge of law arranged? What is the difference between the process of obtaining this knowledge, that is, legal thinking, from other intellectual procedures? What impact do extra-scientific forms of legal knowledge, including legal awareness, have on the process of legal thinking? What are the industry specifics of legal knowledge and cognition? And also many other problems associated with scientific, everyday, trivial, professional knowledge present a problem of legal epistemology. But, once again, attention should be paid to the fact that today to solve the issue of the prospects of digitalization of law enforcement, the most important problem for legal epistemology is the problem of correlation of norm and fact, due and existing, rule and deed, and, most importantly, the nature of understanding of legal norms and legal facts, since it is the understanding procedure that is the main one for law enforcement thinking and cognition.

\section{Theoretical and Methodological Foundations of the Study}

The possibility of using artificial intelligence at the present stage of its design, more precisely, the justification for this possibility and the limits of its use, is due to the study of the epistemological characteristics of legal thinking, the logical aspects of law enforcement, the logical analysis of legal thinking, and law enforcement knowledge. The fact is that artificial intelligence does not have the most important prerequisites, properties and qualities of human intelligence and consciousness, namely, the subconscious, experiencing, fear of death and loss of loved ones, compassion, feelings, emotions, intuitions, in a word, all that underlies human understanding, sense formation and creativity. It is the creative component of thinking, the irrational basis of decision making that is especially important in jurisprudence.

The solution to the question of AI inevitably comes down to the problems of legal epistemology, the philosophy of knowledge and legal thinking. If law enforcement obeyed the logic, it would be entirely possible to introduce artificial intelligence technology into legal activity not only at the stage of preparation for solving a case (collecting information, filling out case materials, summarizing documents, electronic lawsuit, etc.), but also at the stage of making decisions about what AI advocates in jurisprudence "dream" (The legal concept of robotization, 2019). 
In legal literature, there exists and has long been "accustomed" the point of view that the application of a norm to a specific case is a logical procedure and law enforcement activity, considered as intellectual activity, consists of three stages. Wherein, the stage is a strictly defined sequence of committing complexes of actions in the process of law enforcement. Three stages are traditionally distinguished: establishing the factual circumstances of the case; establishing the legal basis of the case; decision of the case. T call the correlation of norm and fact in legal thinking the term "subsummation" is traditionally used in Western European literature (Alexy, 2003; Schauer, 2010; Stuck 1998), in domestic jurisprudence the concept of "qualification" is used (Cherdantsev, 2012).

The majority of authors - representatives of the domestic and foreign theory of legal philosophy consider the law enforcement process as a deductive, syllogistic conclusion. "The logical structure of the court decision goes from the big premise, through the small premise, to the conclusion. The psychological process in a court decision begins with a small premise and goes through a large premise, to a conclusion." (Cherdantsev, 2012: 703-704). This point of view was formed long before the modern era: even in pre-revolutionary monographs on law enforcement: "The logical structure of a court decision is nothing more than a syllogism in which the rule of law and the small premise play a specific everyday relationship" (Shershenevich, 1912: 699).

The court decision was analyzed from the point of view of the logical relationship of the big premise to the minor premise and the following correlation in the Soviet years: "From the formal logical side, the decision of a legal case is an inference in which specific facts (circumstances of the case) are brought under the rule of law" (Alekseev, 1973: 281). The intellectual process, called erroneously psychological, seemed to be strictly rational, excluding any creative, irrational, intuitive, evaluative principles.

In the XX century, this point of view still existed and accepted: until now, textbooks on the theory of state and law specifically consider the procedure for making law enforcement decisions as a syllogism. The process of its search is presented as a conclusion, where a legal norm is a big premise - a judgment, factual circumstances or a life case - a small premise, and the enforcement decision is a conclusion of a logical conclusion. Meanwhile, to attribute the enforcement conclusion to a type of syllogistic conclusion is quite controversial, since the law enforcement procedure or law enforcement process only resembles a deductive conclusion outwardly, while by its nature it is not a logical thinking procedure. Here it should be pointed out that the presentation of the law enforcement process as a logical conclusion was necessary to recognize the objectivity of legal thinking: if law enforcement is a deductive conclusion, then legal qualification can be considered from the point of view of truth and objectivity (Ovchinnikov, 2003). For legal positivism, recognition data play a key role, as the rule of law requires strict adherence and strict observance of the law in each specific situation. However, if we recognize that the law enforcement process is not a logical procedure, but a creative activity that adjusts a fact of life to a certain norm, and at the same time, legal intuition acts as a criterion for the correctness of the fit, then the significance of the law for regulating public relations decreases and the importance of law enforcement increases (Ovchinnikov, 2002). By the way, in this case, artificial intelligence, built on logical principles, has no place in law enforcement.

In fact, enforcement only looks logical in appearance, not being a logical procedure in nature. The application of law in a rational form, being the subject of rational logical research, really looks like a syllogism, but in fact it is not. Indeed, it is very convenient to present a law enforcement decision in the form of a syllogism, a logical conclusion to "calm" doubts about the objectivity of legal qualifications. S.I. Vilniansky believed that "the objectively correct application of laws requires the application of logic" (Vilniansky, 1948: 110). A similar point of view is expressed by S.S. Alekseev: "The characterization of a decision as a conclusion made according to the rules of syllogism is essential for the consistent approval of the principles of socialist legitimacy" (Alekseev, 1973: 281).

In fact, inference does not imply a subjective factor, since inference is made with logical necessity. But from what we call gold a piece of stone, it does not turn into gold. S.S. Alekseev himself emphasizes creativity in the application of law: "If you do not see certain creative moments in solving specific cases ... then the role that legal practice plays in legal regulation will be completely incomprehensible ... So, the solution of legal cases is something bigger and more significant than simple logical actions to solve syllogisms" (Alekseev, 1973: 284-285). However, the recognition of the creative nature of law enforcement did not lead to the recognition of its implicit law-making status. Apparently, solely due to the positivist formalism, the law-making nature of law enforcement was rejected.

For deductive reasoning, both premises must be true. In the case of application of the rule of law, the first premise (disposition of the norm) and the second premise (actual case) cannot be considered as a syllogism, since a prescriptive judgment (norm or disposition) cannot be considered as a statement that has the criterion of 
truth or falsehood. This is a command, a duty, a precept.

The fact is that the statement and its object can be in two opposite relations between each other: either from the point of view of truth (falsity), or from the position of assessment (Ivin, 1987: 32). In the first case, the starting point of the comparison is the object, the statement acts as its description and is defined in terms of truthful concepts. "The concept of truth characterizes the other side of the relationship of the subject to the object, the relationship is theoretical. It qualifies the correspondence of knowledge about an object to the properties of the object itself ..." (Kurbatov, 1991: 109). This is descriptive knowledge. It can be true or false in the description of the object. This knowledge is the result of thinking, the objects of which are positive law, the relationship of its norms, system, etc.

In the second case a statement that functions as an assessment, standard, plan is the initial is. Correspondence to it of the object is stored in value terms. The basis of the assessment is value - an object significant for a particular person. Prescriptive knowledge cannot be true or false, it does not describe anything. In the first case, appeal to the subject of argumentation is necessary (since value is the correspondence of an object to the requirements of the subject), and in the second case, the elimination of everything subjective is necessary (since cognition of the object requires universal). In the first case, this is the knowledge not about the object, but about oneself, more precisely, about the attitude to any phenomena on its part. Therefore, one cannot disagree with V.I. Kurbatov, who believes that "attributing the value of truth criteria to the highest degree is incorrect" (Kurbatov, 1991: 113).

Further, in the case of law enforcement, deductive syllogism would be probable if all situations possible in social reality were described by a finite set. That is, a purely logical process would be possible if the general norm were completely and completely suitable in its features for a particular case (and features that do not require evaluation), and there would be no problems with its relevance to it. It is no coincidence that Roman jurisprudence clearly adhered to the doctrine: "the law always needs interpretation, and it should be the work of knowledgeable lawyers" (Chernilovsky, 1989: 6). In fact, this is a sign of distrust of the possibilities of one rule to be suitable for all occasions. In modern legal literature devoted to the interpretation of legal norms, the need for the latter in each case of the realization of law is recognized. The fallacy of the principle "only obscure laws are subject to interpretation" is also accepted (Cherdantsev, 1979).

\section{Main Part}

The rule of law is only a hint to the law enforcer, creatively eliminating certain features of the incident that do not coincide with the hypothesis, determining their importance intuitively. R. Lukich quite rightly points out: "as a rule, almost every norm, even to a minimum degree, changes its meaning when applied in specific cases, each of which has its own distinctive features" (Lukich, 1981: 292). For example, in order to identify purely logically in a continuous stream of signs of a situation those that have a legal status, that is, form the actual composition required by the norm, it is necessary to know the norms that strictly indicate them. It's good if the law clearly defines these signs (as, say, the age of criminal responsibility), but if they are evaluative or require analogy due to the fact that the legislator cannot provide for all of their types (for example, list all cases of "force majeure"), then the process of comparing the actual and legal circumstances of the case assumes an intuitive, rather than strictly logical, character. More precisely, it takes the form of a logical and rational one, but only to certain boundaries: to the borders of common sense, evidence, intuition, "general feeling".

Almost all crime elements have evaluative concepts in their possession, and this cannot be avoided. It is logically impossible to evaluate the "nature of violence" in the case of delimitation of robbery from robbery, the "voluntariness" of the transaction, "the sufficiency of evidence", "selfish motive" and so on. Therefore, the process of legal cognition seems to be more hermeneutical, and not strictly logical, due to the presence of a huge number of evaluative concepts in law, the need for which is due to the diversity of human relationships. In each new case, the meaning of these concepts, as well as of the whole norm, will be redefined, therefore, with a simple reading that is not related to application, "only the general and abstract meaning of the rule of law is captured ... In this case, the feeling of acquaintance with the word is taken as a process of understanding" (Cherdantsev, 1979: 13). Not to mention the fact that the nature of the punishment or obligation must be in each case, first of all, fair, "equivalent" to the damage or authority of the opposite party.

The limited character of logic and the evaluative nature of legal thinking, in our opinion, are even more evident in the case of analogy. Creating a new norm on the basis of existing ones more clearly demonstrates the general features of the processes of filling the gap in law and interpretation.

Bringing the case under the rule in the presence of full correspondence between them I. Kant attributed to the simplest form of human cognitive ability - reason. Logically thinking, "imagining something by means of concepts", that is, possessing the "right mind" is enough for a servant or official to carry out certain orders (Kant, 
1966: 437). But it's another matter when the norm of positive law contains only a general rule and the creation of a particular norm is necessary to solve this case. Or there is a "gap" of law and we need an analogy of the law, or an analogy of law. The thing that is needed here is what I. Kant called the ability of judgment: "An officer who is prescribed only a general rule for the case entrusted to him and who must decide for himself what to do in this or that case, must have the ability of judgment ..." (Kant, 1966: 438).

In fact, if the application of the norm, and in the case of the slightest discrepancy with the described situation in the norm, would already have an analogy to some extent, were logical, then clear rules would be necessary that would describe the criteria for matching the signs of the situation that is normal, and signs of the existing situation. That is, we need rules by which it would be possible to recognize whether the rule is suitable for this case or not. "And this would put aside the question," according to the apt remark of I. Kant, "more and more to infinity" (Kant, 1966: 437). Therefore, the basis of the analogy is a complex thought process in which discursive and evaluative thought acts are intertwined, which allows us to talk about the impossibility of complete abstractness, abstractness of legal thinking, such as mathematical thinking.

As another argument, the axiological, and therefore the creative, subjective nature of the implementation of the principles of law should be pointed out. From the technical and legal point of view, the principles constitute guiding legal ideas that express the basic legal views, ideals, values of the state on the nature of law and the regulation of public relations, on the priorities of legal policy, from the philosophical and legal point of view these are imperatives that protect the most important, absolute legal values. All of them arose under the influence of certain ideas, ideals, ideologies.

For example, the principle of equality of spouses in the history of family law originates from the legal consolidation of the Christian system of values, where for the first time in the history of mankind the dignity of the human person is protected regardless of gender, ethnicity or faith (Fominskaya, 2019). The principle of the right of nations to self-determination arose in the worldview of thinkers of the origin of nationalism of the Enlightenment, etc. The ideological foundations of law and order are given a lot of attention by modern researchers (Klimenko, 2019a). The implementation of the principles of law is carried out already at the stage of their normative consolidation: "in order for the principles to be normative in nature, first you need general guiding ideas of law that are not fixed by law, and then the principles of law as fundamental ideas in order to most correctly and adequately reflect social reality in in accordance with the current level of knowledge in society, they must exist in a certain form of law" (Klimenko, 2019b).

Therefore, the principles of law do not constitute ordinary rules of law, but create the right background, context for the implementation of the rules of law thanks to the axiological activity of the legal realization. V.V. Ershov notes, and it is quite fair, that the principles of law cannot be identified with the rules of law, because, unlike the rules of law, the principles of law are characterized by fundamental nature, the maximum level of generalization, constancy, stability, maximum exemption from specificity and particularities, universality and objective character (Sakhapov, 2014). The universality of the principles of law allows you to create a correct interpretation of the rule of law from the point of view of the legislator by defining the context for understanding the rule of law.

It is no coincidence that the Constitutional Court of the Russian Federation in the Decree of January 27, $2004 \mathrm{~N}$ 1-P indicated: "The general principles of law, including those embodied in the Constitution of the Russian Federation, have the highest authority and are a criterion and measure for assessing the legality of all normative acts"1. These general principles of law can be found not only in the text of the Constitution of the Russian Federation, but also in the ideology of constitutionalism, in its doctrine. However, the objectivity of the origin of the principles of law is not shared in the whole spectrum of theories of law: psychological, sociological, historical, etc. Cognition, or rather interpretation, of the principles of law is even more biased by their contextuality and subjectivity of the interpreter, which AI does not have.

For AI, the contextuality of the principles of law is not achievable, however, it is extremely necessary in law enforcement. It cannot have contextual intellectual procedures programmed, since the ratio between the norm and the context of its interpretation implies a break through the hermeneutic circle in which the norm is considered to be a part and the context of the norm (industry principles) is accepted as a whole.

\footnotetext{
${ }^{1}$ Resolution of the Constitutional Court of the Russian Federation of 01.27.2004 N 1-P. "In the case of the constitutionality of certain provisions of paragraph 2 of the first part of Article 27, parts one, two and four of Article 251, parts two and three of Article 253 of the Civil Procedure Code of the Russian Federation in connection with a request from the Government of the Russian Federation"(2004) Rossiyskaya Gazeta, N 18, 02/03/2004.
} 
Difficulty in using rational methods also arises in connection with the fuzziness and uncertainty of modern legal understanding and the doctrine of the sources of law. Of course, here we are talking about a conflict of broad and narrow regulatory approaches to law. Legal positivism is based on the "mysticism" of law enforcement syllogism, which supposedly exists in reality. There is no way to talk about this in detail, since earlier one of the authors has already resorted to the analysis of deontic logic in legal thinking (Ovchinnikov, 2019).

It should only be pointed out that the proponents of legal positivism would not want to limit law enforcement and fact in reality this process is multi-level in nature. For example, even if there is no reference to custom, an understanding of the meaning of the rule of law, the meaning of the construction of norms, legal thinking still takes them into account.

\section{Conclusions}

The developer of AI in justice, who is faced with a discussion of legal understanding, should be a supporter of a broad (integrative) approach to law, to understand that not only the rule of law, but also legal entities form the concept of law. The latter should include not only the norms of customary law, judicial practice, but also the norms of public law, natural law, the norms of contract law, the norms of corporate law, the norms of business customs, normative formations of legal doctrine, principles of law, ideas and values of law, normative formations of interpretative acts. In our deep conviction, they all have features from the point of view of their implementation, application, and, therefore, understanding. All legal entities constitute the contextual meaning of legal norms. It is hardly possible to take them into account in the process of creating AI programs.

It is hardly possible to take into account AI principles of international law, constitutional law, in unity with which law enforcement and interpretation activities should be carried out. Both the principles of international law and the norms of the Constitution of the Russian Federation, in which the "principles" of law are "hidden", require concretization as sometimes they appear in specific cases in the process of involving the norms of constitutional law in the interpretation of particular norms.

It is also necessary to pay attention to the preambles of normative legal acts, which also play the role of the principles of law - the fundamental principles of legal regulation. It is legal consciousness and its legal thinking that concretizes these means and methods of legal regulation. Some authors deny their regulatory significance, but we do not agree with them. They constitute the context of interpretation of the norms of a legal act. The preamble, in our deep conviction, is the connection of a normative act with other normative acts, or with the idea of natural law, if we are talking about the Constitution, for example, and the justification of the legal force of the act. In addition, the preamble gives meaning to the relations within the normative legal act, performs the function of goal-setting. And if one or another legal norm is contrary to the preamble, then the preamble should be applied primarily.

It should be born in mind that this process is creative in nature, which AI lacks. Often (always in the presence of evaluative concepts) it is impossible to establish the correspondence of norm and fact with the help of logic. Therefore, it is necessary to observe the principles of justice and expediency, contextuality and common sense, intuition of law and good faith.

\section{References}

Alekseev, S. S. (1973). Problems of the theory of law: A course of lectures in two volumes. T. 2. Sverdlovsk: Ural State University.

Alexy, R. (2003). On Balancing and Subsumption: A Structural Comparison. Ratio Juris., 16(4), 433-439. https://doi.org/10.1046/j.0952-1917.2003.00244.x

Beketov, A. (2019). Artificial intelligence in court. Retrieved from https://ru.euronews.com/2019/01/28/ eu-robojudge-courts

Cherdantsev, A. F. (1979). The interpretation of Soviet law. Moscow, Yuridicheskaya literatura.

Cherdantsev, A. F. (2012). Logical and linguistic phenomena in jurisprudence. Moscow, Norma; Infra-M.

Chernilovsky, Z. M. (1989). Introduction Bartoshek. Moscow, Roman law (Concepts, terms, definitions). Moscow, pp. 5-10.

Fominskaya, M. D. (2019). Spiritual and moral foundations and prerequisites of "personality dignity" as a legal category. Bulletin of the Law Faculty of the Southern Federal University, (1), 8-14.

Ivin, A. A. (1987). Values and understanding. Questions of philosophy, (8), 31-43.

Kant, I. (1966). Works. In 6 volumes. T. 6. Moscow, Thought. 
Klimenko, A. I. (2019a). The ideological foundations of law and order. Law and order and its institutional foundations Proceedings of the international scientific conference. pp. 11-17.

Klimenko, A. I. (2019b). The problem of legalization of values. Public-law forms and methods of socialization of a person. Proceedings of the All-Russian Scientific Conference. pp. 5-11.

Kurbatov, V. I. (1991). Socio-political argumentation (Logical and methodological analysis). Rostov on Don.

Lukich, R. (1981). Methodology of law. Translation from Serbo-Croatian.

Mamycheva, A. Yu. (Ed.). (2020). The World in the Digital Age: Politics, Law, Economics. Moscow, RIOR.

Mamycheva, A. Yu., Modovtseva, A. Yu., \& Petruk, G. V. (Eds.). (2020). Robots claim their rights: doctrinal legal principles and moral and ethical standards for the use of autonomous robotic technologies and devices. Moscow, RIOR.

Ovchinnikov, A. I. (2002). Legal thinking in the hermeneutic paradigm. Monograph. Rostov on Don: Publishing house Rostov State University.

Ovchinnikov, A. I. (2003). Legal thinking: theoretical and methodological analysis. Rostov on Don: Publishing house Rostov State University.

Ovchinnikov, A. I. (2019). Artificial Intelligence in the Law Enforcement Process: An Epistemological Analysis of Opportunities and Limitations. Legal Understanding in the Digital Age: Artificial Intelligence in the Implementation of Law in Law Enforcement: Collection of Articles. Moscow, pp. 133-142.

Sakhapov, R. R. (2014). The main approaches to understanding the principles of law in Russian legal science (Soviet and modern periods). History of State and Law, (15), 10-15.

Schauer, F. (2010). Balancing, Subsumption, and the Constraining Role of Legal Text. Law and Ethics of Human Rights, 4(1), 34-45. https://doi.org/10.2202/1938-2545.1043

Shershenevich, G. F. (1912). General theory of law. Moscow.

Stuck, H. (1998). Subsumtion und Abwagung. Archiv fur Rechts- und Sozialphilosophie. Bd. 84. H. 3.

Tikhomirov, Yu. A., \& Nanba, S. B. (Eds.). (2019). The legal concept of robotization. Moscow, Prospect.

Vilniansky, S. I. (1948). The value of logic in the application of legal norms. Scientific notes Kharkov. legal inst., (3), 100-290.

\section{Copyrights}

Copyright for this article is retained by the author(s), with first publication rights granted to the journal.

This is an open-access article distributed under the terms and conditions of the Creative Commons Attribution license (http://creativecommons.org/licenses/by/4.0/). 